\title{
PSYCHE
}

\begin{tabular}{lcc}
\hline Vol. 93 & 1986 & Nos. 3-4 \\
\hline
\end{tabular}

\section{THE CHOICE OF WEB-MONITORING SITES BY A GREEN MIAGRAMMOPES SPECIES (ARANEAE: ULOBORIDAE)*}

\author{
By BRENT D. Opell \\ Department of Biology \\ Virginia Polytechnic Institute and State University \\ Blacksburg, Virginia 24061
}

\section{INTRODUCTION}

The varied and effective predatory strategies of spiders have drawn more attention than have their antipredator adaptations to threats from birds, wasps, damselflies, and other spiders (Bristowe 1941, Dorris 1970, Blanke 1972, Jackson \& Blest 1982a, b). As the majority of their predators are visual hunters, it is not surprising that many spiders employ either protective resemblance or eucrypsis (as defined by Robinson 1969a) to escape detection. In general, protective resemblance seems to be more common among spiders that use a capture web and eucrypsis among hunting spiders that employ sit-and-wait tactics. Protective resemblance usually involves anatomical modification and is frequently enhanced by postural specializations (Robinson 1969b). Both of these antipredator adaptations are often enhanced by a spider's color.

In order for protective resemblance and eucrypsis to be effective, animals employing these strategies should select a background whose color or texture closely matches their own. Such background selection has been demonstrated for adult moths (Kettlewell 1955, Sargent 1966, 1984; Sargent \& Keiper 1969, Malcom \& Hanks 1973), butterfly pupae (West \& Hazel 1979), and grasshoppers (Giles 1982). Several studies have demonstrated the protective

\footnotetext{
*Manuscript received by the editor May 16, 1986
} 
benefits of correct background selection in both immature and adult insects (Hazel \& West 1979, Erichsen et al. 1980, West \& Hazel 1982, Sims \& Shapiro 1983a, b). This study investigates background selection by spiders of the genus Miagrammopes.

Members of the tropical genus Miagrammopes spin reduced capture webs consisting of a horizontal thread which may either be sticky or non-sticky and may have one or several vertical or diagonal sticky (cribellar) capture threads extending from it (Lubin et al. 1978, Opell 1984). These spiders monitor their reduced webs from one of the attachment points, where their postures and body form make them cryptic. Brown species that spin their webs among twigs and vines resemble thorns or broken twig bases, whereas green species that spin webs on moss-covered vegetation resemble extending moss phyllidia (Fig. 1). After subduing and wrapping prey, these spiders return to one of their web's attachment points and resume their typical cryptic posture while feeding.

Most individuals of the green Miagrammopes species I observed in Costa Rica monitored their webs from moss-covered twigs. This occurred despite the fact that some webs were also anchored to bare twigs. In order to test the hypothesis that members of this species select moss-covered twigs over bare twigs as web-monitoring sites, I conducted a series of choice experiments.

\section{Materials AND MethodS}

The species used in this study is an undescribed member of the Miagrammopes aspinatus species group (Opell 1984). Voucher specimens are deposited in Harvard University's Museum of Comparative Zoology. Spiders used in this study were collected from stands of abandoned cacao (Theobroma cacao) at the Organization for Tropical Studies' La Selva research station located near the town of Puerto Viejo de Sarapiqui, Heredia Province, Costa Rica. Prior to their release onto experimental frames, these spiders were kept for two to four days in small, cotton stoppered glass vials. During this time, their carapace and leg lengths were measured with a micrometer-equipped dissecting microscope. Because adult males do not spin capture webs, only immatures and adult females were used in this study.

Experimental frames (Fig. 2) were constructed of $2 \mathrm{~mm}$ diameter hardwood applicator sticks glued together with epoxy and bound 


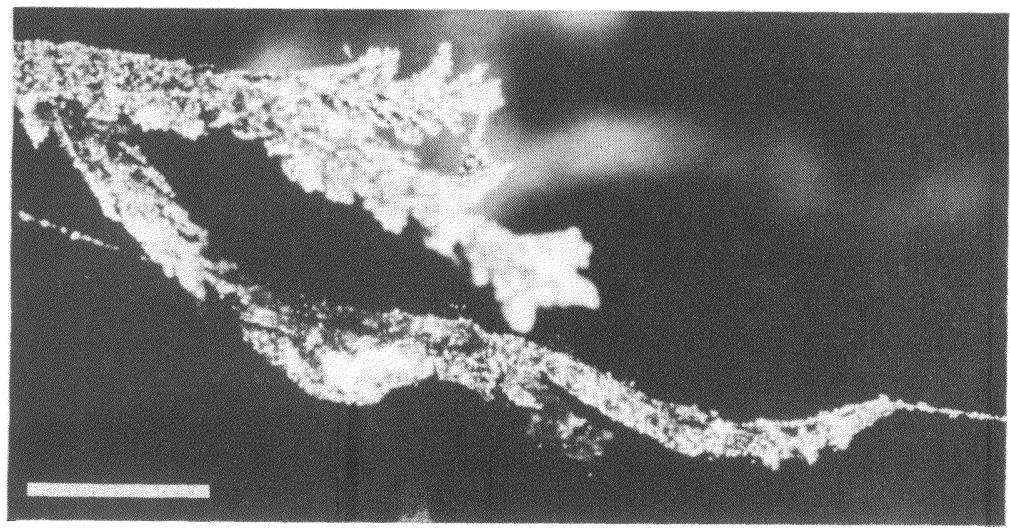

Figure 1. Adult female Miagrammopes sp. feeding on a small beetle held with the pedipalps while monitoring an attachment line of the capture web. Setal tufts at the distal end of the extended first legs make them resemble the moss to which the web is attached. Scale bar represents $2 \mathrm{~mm}$.

by thread. To one set of opposite vertical elements were wired mosscovered cacao twigs and to the other set, bare cacao twigs. All twigs were taken from the same tree and had a diameter of about $7 \mathrm{~mm}$. Two of the four frames employed bare twigs that had no evidence of moss cover and two twigs whose moss covering was removed without damage to the bark. Frames hung $98 \mathrm{~cm}$ apart along a taut, north-south suspension line. To account for the possible influence of air currents, frames were oriented so that the moss-covered twigs occupied alternate sectors (East and West sectors, North and South sectors, etc.).

From 26 June until 6 July 1985, these frames hung in the abandoned cacao plantation from which specimens were collected. From 7-15 July 1985, these study frames were transferred to a roofed enclosure (cabina) whose screened north, east, and south walls were covered with light colored curtains to exclude direct sunlight. Here, frame orientation and spacing were identical to that described above. In this enclosure, spiders were exposed only to natural light. Each frame's bare and moss-covered twigs were watered daily at about 8:30 and 13:00. At the end of the study, moss on the twigs showed no signs of thinning or turning brown and bare twigs showed no signs of moss growth. 


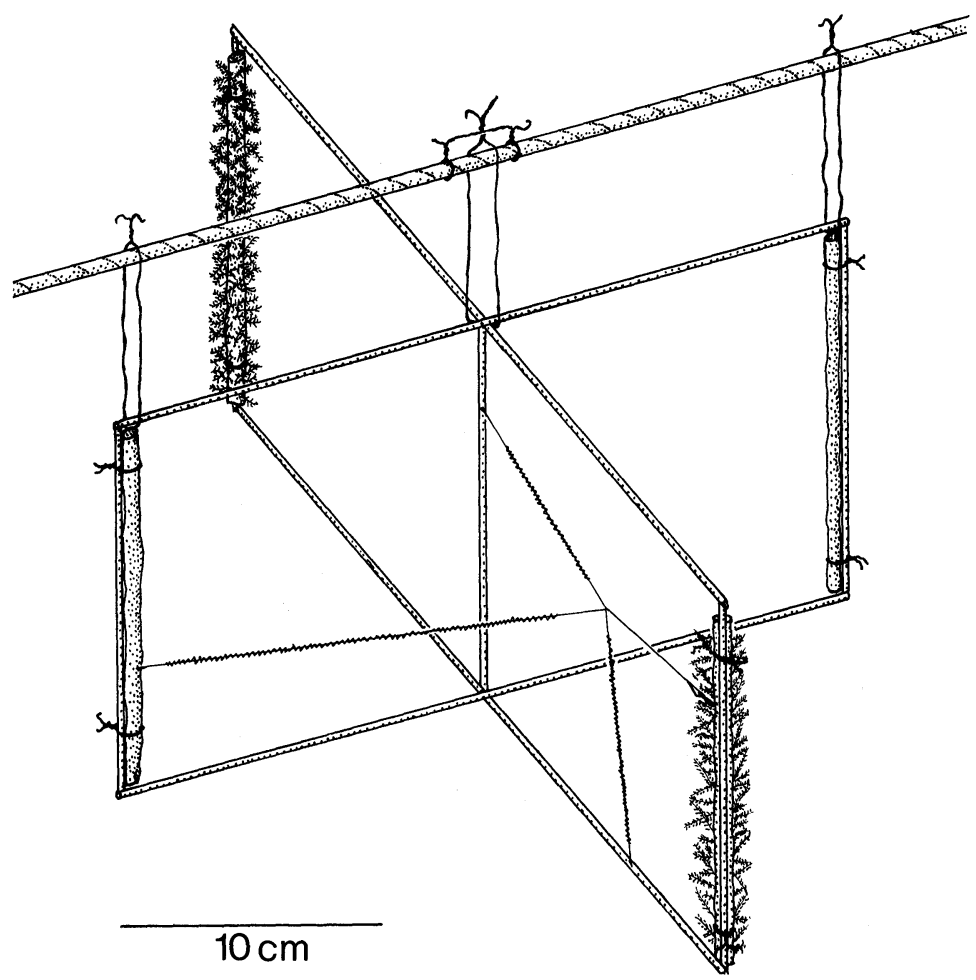

Figure 2. Diagram of the frame used in this study, showing a spider monitoring its web from the front, moss-covered sector.

Frames and suspension lines were cleaned of all visible silk strands before spiders were released at 16:00 onto the top center of each frame. Frames were checked the following morning at 8:00 and the presence of webs and position of spiders recorded. A capture web was defined as a web with sticky (cribellar) prey capture silk. In contrast with the non-sticky, single-line resting web, the capture web usually consisted of multiple, diverging threads. Spiders always hung near one of the web's attachment points (Fig. 1) and it was noted whether this was a moss-covered or bare site. During the first three days and last day of the study only a single specimen was released onto each frame. On other days, one large and one small specimen were released on each frame. This was done to compensate 
for what initially promised to be a high percentage of spiders leaving the frames. The size difference made it possible to distinguish individuals on each frame and to record which had made a web. After web production and position were recorded specimens were collected and released in the forest. A plot of first femur length against carapace length for the specimens used in this study plus the values of 61 additional specimens was used to assign the instar values to spiders. Chi-square tests were used to evaluate the results of this study.

\section{RESULTS}

Earlier instars were more commonly found than later instars and, therefore, are represented by a larger sample size. Of the 21 capture webs constructed in the forest, nine were spun by third instars, six by fourth instars, four by fifth instars, one by an adult female, and one by a specimen of uncertain age. Of the 28 capture webs spun in the enclosure, four were spun by third instars, 14 by fourth instars, six by fifth instars, and four by adult females. Significantly more $(0.05>p>0.025)$ spiders produced capture webs in the enclosure than in the forest (Table I). All capture webs made within frames were monitored from a moss-covered twig. In the enclosure, six specimens constructed their capture webs outside the frame and monitored them from wires used to attach frames to the support line. In most of these cases, the spider's web was not anchored to a moss-covered twig and the highest attachment point was the favored monitoring site. When these six capture webs are compared with the other 22 indoor webs monitored from moss, moss is still the favored site $(0.025>\mathrm{p}>0.01)$.

In neither habitat was there a significant difference in the mosscovered frame sectors from which webs were monitored (Table I). However, these results were more clear-cut in the enclosure $(0.975>$ $\mathrm{p}>0.90)$ than in the forest $(0.50>\mathrm{p}>0.10)$. In the latter setting, moss-covered twigs on East and South frame sectors appear to be favored. This may be explained by stronger and/or more unidirectional wind currents in the latter setting. On seven occasions I used a web dusting device to expel a cloud of corn starch into the air of the forest site. On three instances the wind was blowing to the east, on three to the southeast, and one to the southwest. These observations suggest that a spider's dragline had a greater chance of being carried 


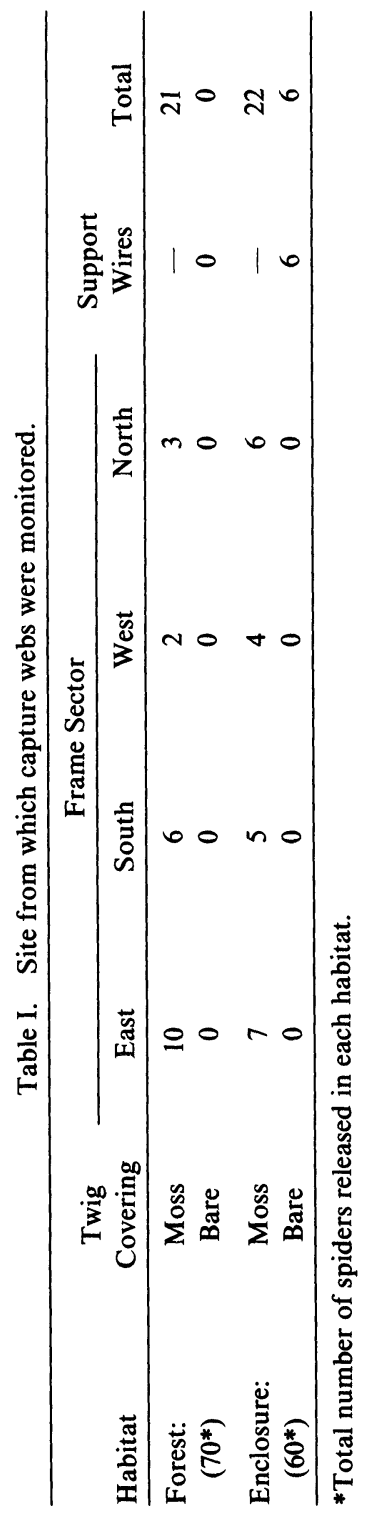


to a frame's East and South sectors and that, when moss-covered, the twig attached to this sector would be favored over the opposite moss-covered twig as a web-monitoring site.

\section{Discussion}

This species' preference for moss as a web-monitoring site enhances its protective resemblance. The exposed first legs of these green species have a tuft of green tibial setae that look like the small phyllidia of an extending moss plant (Fig. 1). Although these setal tufts are found in brown Miagrammopes species, they are more prominent in green species, where they become disproportionately larger in subadult and adult individuals. During the night Miagrammopes often abandon their typical day-time position adjacent to a twig and hang on the monitoring line a centimeter or more from its attachment point to a twig.

Choice of a web-monitoring site by Miagrammopes is facilitated by the fact that most of their simple, irregular webs have no single attachment point from which they must be monitored. A few webs have a particular thread that probably serves as an optimal monitoring line by virtue of its single attachment point to several diverging lines. However, most newly constructed Miagrammopes webs consist of an approximately horizontal thread with one or several independently diverging vertical or diagonal threads. Either end of this horizontal thread could serve as a monitoring site. I have seen disturbed Miagrammopes run to the opposite end of their horizontal threads and begin monitoring their webs from this new position.

The greater number of missing individuals noted in the forest than in the enclosure experiments probably resulted from a higher rate of spiders ballooning from the forest frames. Three factors suggest that this difference is not due to predators removing spiders that chose bare twigs as web-monitoring sites. First, release and observation times were chosen so that most of site selection and web construction took place at night when threats from visually hunting predators were lowest. Second, during this study, no predatory insects were seen on the experimental frames or their supporting lines. Third, none of the spiders in the predator-free enclosure chose bare twigs as web-monitoring sites.

This study does not address the mechanism by which individuals select moss-covered twigs. Experimental studies on cryptic insects 
show that two methods may be used in selecting a matching background. Gillis (1982) showed that in one grasshopper species individuals select backgrounds whose color matches that of their circumocular regions. By contrast, Sargent (1968) found that background selection in some moths was hereditary and was unaffected by painting their circumocular scales. Color vision has not been demonstrated in Miagrammopes. However, the eyes of the species used in this study are well developed and have low f-numbers, indicating that they are effective in low light intensities (Opell and Cushing, in press). Tactile or moisture properties of the moss may also be important cues for its choice as a web-monitoring site. Unlike striped moths that must assume the proper orientation in order to take full advantage of their cryptic markings (Sargent 1969), the webs of Miagrammopes assure that they will assume the proper attitude after they have selected the correct background.

\section{SUMMARY}

Members of the spider genus Miagrammopes construct simple capture webs consisting of only a few threads and assume a sticklike posture as they actively monitor these webs. A green Costa Rican species showed a statistically significant preference for mosscovered twigs as web-monitoring sites. This choice was observed in both a forest setting and a screened enclosure, and occurred on experimental frames which required spiders to attach their webs to both bare and moss-covered twigs.

\section{ACKNOWLEDGEMENTS}

I am grateful to the Organization for Tropical Studies for permitting me to use its facilities and to David and Deborah Clark, codirectors of the organization's La Selva research station, for their help. This study was supported by National Science Foundation grant BSR-8407979 to the author.

\section{REFERENCES}

BLANKE, R.

1972. Untersuchungen zur Ökophysiologie und Ökethologie von Cyrtophora citricola Forskal (Araneae, Araneidae) in Andalusien. Forma et Functio, 5: 125-206. 
BRISTOWE, W. S.

1941. The Comity of Spiders. Ray Soc., No. 128. London.

DorRIs, P. F.

1970. Spiders collected from mud-dauber nests in in Mississippi. J. Kansas Ent. Soc., 43: 10-11.

Erichsen, J. T., J. R. Krebs, AND A. I. Houston.

1980. Optimal foraging and cryptic prey. J. Anim. Ecol., 49: 271-276.

Gillis, J. E.

1982. Substrate color-matching cues in the cryptic grasshopper Circotettix rabula rabula. Anim. Behav., 30: 113-116.

Hazel, W. N. AND D. A. West.

1979. Environmental control of pupal colour in swallow-tail butterflies (Lepidoptera: Papilioninae): Battus philenor (L) and Papilio polyxenes Fabr. Ecol. Entomol., 4: 393-400.

JACKSON, R. R. AND A. D. Blest.

1982a. The biology of Portia fimbriata, a web-building jumping spider (Araneae, Salticidae) from Queensland: utilisation of webs and predatory versatility. J. Zool. (London), 196: 255-293.

1982b. The distances at which a primitive jumping spider, Portia fimbriata, makes visual discriminations. J. Exp. Biol., 87: 441-445.

Kettlewell, H. B. D.

1955. Recognition of appropriate background by the pale and black phases of Lepidoptera. Nature, 175: 943-944.

Lubin, Y. D., W. G. Eberhard, AND G. G. MONTGomery.

1978. Webs of Miagrammopes (Araneae: Uloboridae) in the Neotropics. Psyche, 85: 1-23.

Malcom, W. M. and J. P. Hanks.

1973. Landing-site selection searching behavior in the micro-lepidopteran Agonopteryx pulvipennella. Anim. Behav., 21: 45-48.

OPELL, B. D.

1984. Phylogenetic review of the genus Miagrammopes sensu lato (Araneae: Uloboridae). J. Arachnol., 12: 229-240.

Opell, B. D. AND P. E. Cushing.

in press. Visual fields of orb-web and single-line-web spiders of the family Uloboridae. Zoomorphology.

Robinson, M. H.

1969a. Defense against visually hunting predators. Evol. Biol., 3: 225-259.

1969b. The defensive behaviour of some orthopteroid insects from Panama. Trans. R. Soc. London, 121: 281-303.

SARGENT, T. D.

1966. Background selections of geometrid and noctuid moths. Science, 154: 1674-1675.

1968. Cryptic moths: effects on background selection of painting circumocular scales. Science, 159: 100-101.

1969. Behavioural adaptations of cryptic moths. III. Resting attitudes of two bark-like species, Melanolophia canadaria and Catocala uttronia. Anim. Behav., 17: 670-672. 
1984. Melanism in Phigalia titea (Lepidoptera: Geometridae) in southern New England: A response to forest disturbance? J. N. Y. Entomol. Soc., 93: 1113-1120.

SARgent, T. D. AND R. R. KeIPER.

1969. Behavioral adaptations of cryptic moths, I. Preliminary studies on bark-like species. J. Lepid. Soc., 23: 1-9.

Sims, S. R. AND A. M. Shapiro.

1983a. Pupal color dimorphism in California Battus philenor (Papilionidae): Morphology factors and selective advantage. J. Lepid. Soc., 37: 236-243.

1983b. Pupal dimorphism in California Battus philenor (L): Pupation sites, environmental control, and diapause linkage. Ecol. Entomol., 8: 95-104.

West, D. A. AND W. N. Hazel.

1979. Natural pupation sites of swallowtail butterflies (Lepidoptera: Papilioninae): Papilio polyxenes Fabr., P. glaucus L. and Battus philenor (L.). Ecol. Entomol., 4: 387-392.

1982. An experimental test of natural selection for pupation site in swallowtail butterflies. Evolution, 36: 152-159. 

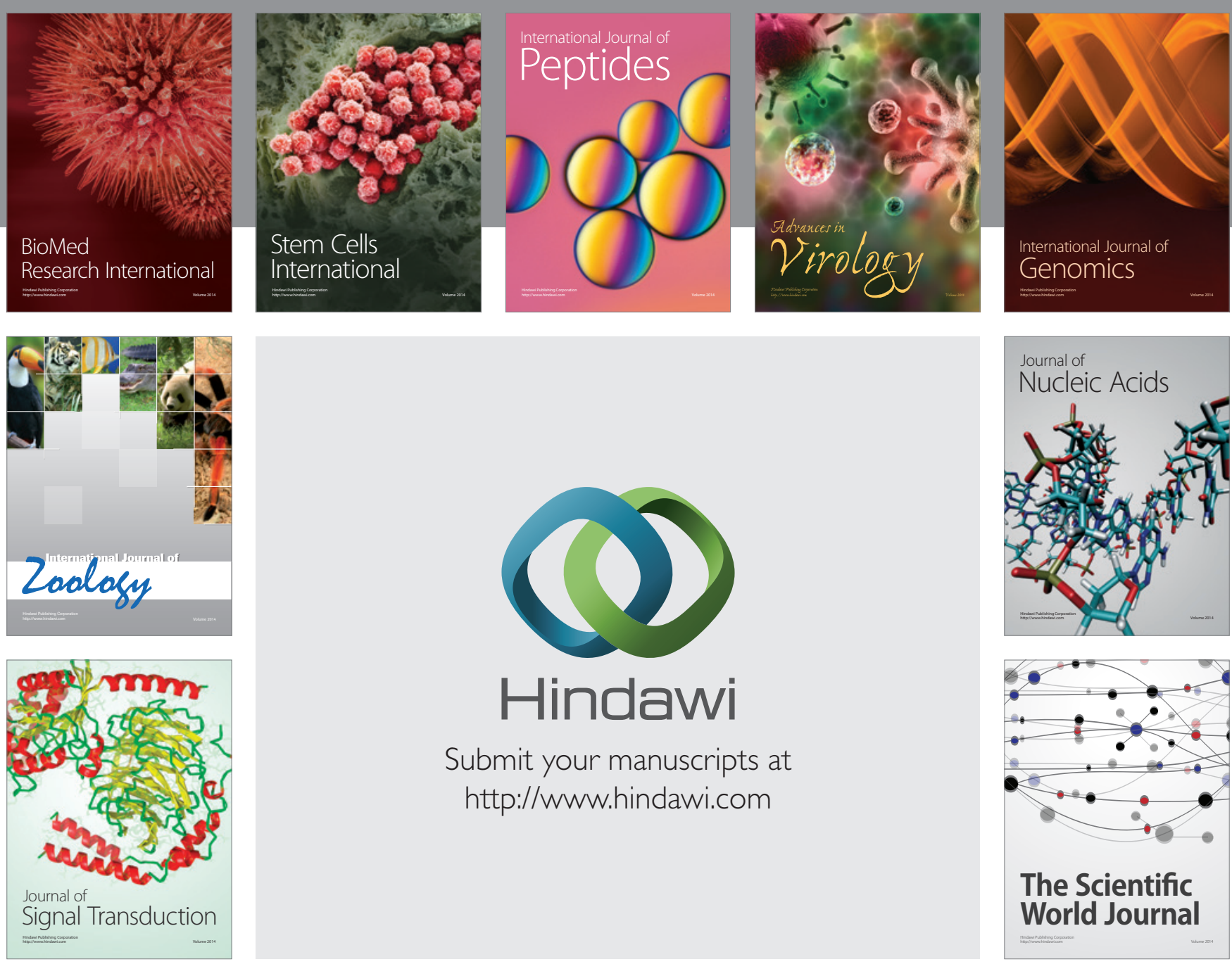

Submit your manuscripts at

http://www.hindawi.com
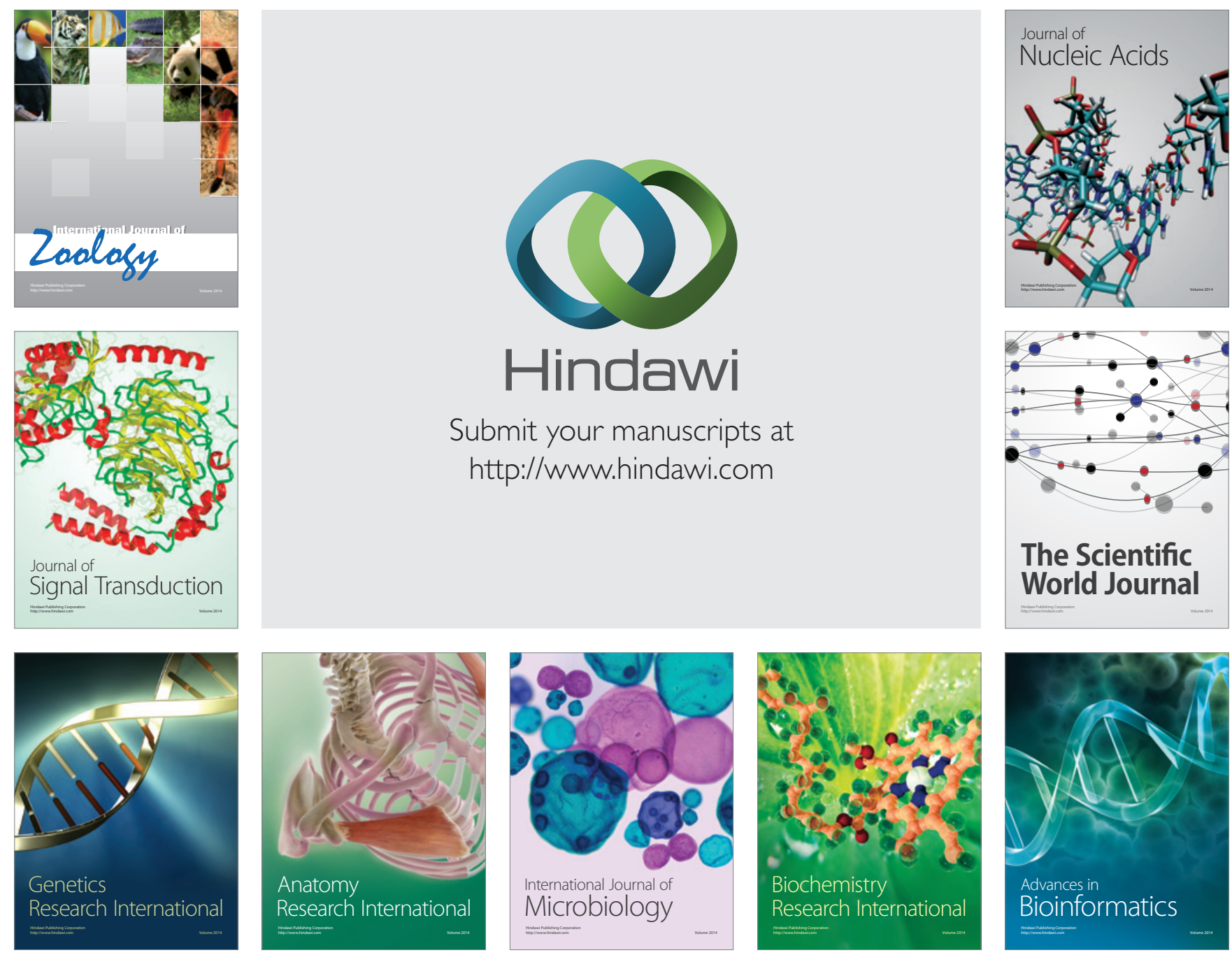

The Scientific World Journal
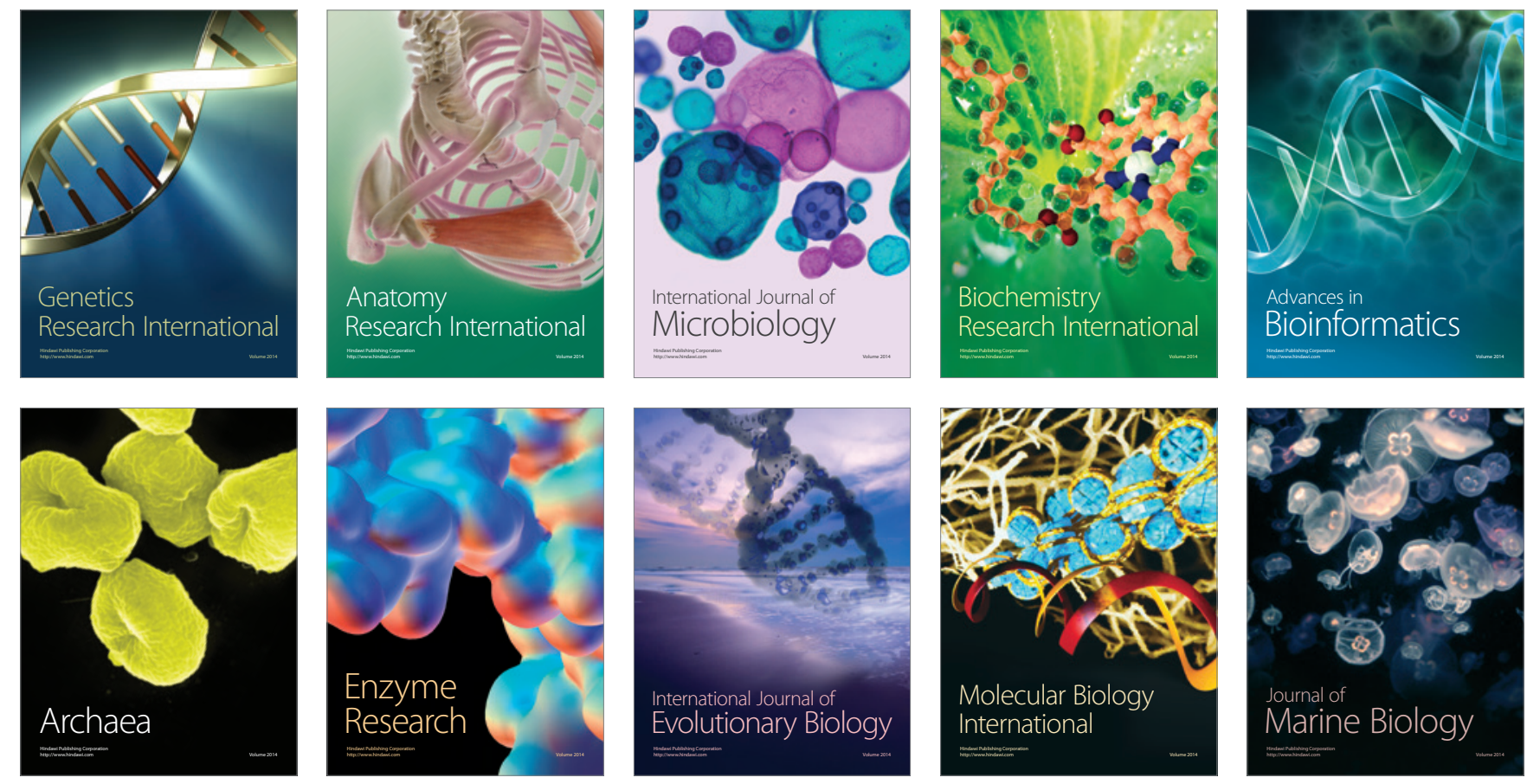